Jurnal Target, Vol. 1, No. 2, 2019

\title{
Pengaruh Job Insecurity Dan Burnout Terhadap Turnover Intentions (Studi Pada Karyawan Daily Worker dan Outsourcing Hotel Bintang 4 (Empat) Di Kota Mataram) \\ Isra' Dewi Kuntary Ibrahim \\ Program Studi Manajemen Universitas Bumigora \\ Email : israibrahim1524@gmail.com
}

\begin{abstract}
Abstrak
Penelitian ini bertujuan untuk melihat pengaruh secara signifikan job insecurity dan burnout terhadap turnover intentions studi pada karyawan dengan status Daily Worker dan Outsourcing pada hotel bintang 4 (empat) di Kota Mataram. Jenis penelitian ini adalah penelitian kausal.Pengumpulan data menggunakan sensus dengan jumlah responden 86 orang. Analisis dan pengujian hipotesis menggunakan Partial Least Square (PLS) dengan instrument penelitian menggunakan kuesioner. Hasil penelitian menunjukkan bahwa terdapat pengaruh positif dan signifikan job insecurity terhadap turnover intentions dan terdapat pengaruh positif dan signifikan burnout terhadap turnover intentions.
\end{abstract}

Keywords : job insecurity, burnout, turnover intentions, hospitality industry, partial least square (pls). 


\section{Pendahuluan}

Hotel merupakan salah satu unsur yang paling penting bagi sektor pariwisata.Ini tidak terlepas dari fakta bahwa industri perhotelan merupakan tulang punggung yang mendukung pembangunan sektor pariwisata. Berikut adalah data tingkat hunian kamar hotel bintang per bulan tahun 2017 dan 2018 di NTB:

\section{Tabel 1}

\section{Tingkat Hunian Kamar Hotel Bintang Di Nusa Tenggara Barat}

Per Bulan Tahun 2017 dan 2018

\begin{tabular}{|l|c|c|}
\hline \multirow{2}{*}{\multicolumn{1}{|c|}{ Bulan }} & \multicolumn{2}{c|}{$\begin{array}{c}\text { Tingkat Hunian Kamar } \\
\text { (Persen) }\end{array}$} \\
\cline { 2 - 3 } & $\mathbf{2 0 1 7}$ & $\mathbf{2 0 1 8}$ \\
\hline Januari & 34,46 & 37,91 \\
\hline Februari & 41,70 & 40,60 \\
\hline Maret & 49,78 & 51,32 \\
\hline April & 51,69 & 52,49 \\
\hline Mei & 50,83 & 54,06 \\
\hline Juni & 41,95 & 46,56 \\
\hline Juli & 54,99 & 0 \\
\hline Agustus & 58,79 & 28,18 \\
\hline September & 53,32 & 34,85 \\
\hline Oktober & 49,85 & 39,21 \\
\hline November & 52,48 & 38,24 \\
\hline Desember & 50,05 & 40,53 \\
\hline
\end{tabular}

Sumber : Berita Resmi Statistik Badan Pusat Statistik (BPS) Nusa Tenggara Barat (NTB) tanggal update terakhir 08 Feb 2019.

Berdasarkan tabel diatas dapat dilihat bahwa tingkat penghunian kamar setiap bulannya dari bulan Januari sampai Desember pada tahun 2017 dan 2018 mengalami gejala fluktuasi. Dapat dilihat bulan Januari sampai Juli rata-rata tingkat penghunian kamar mengalami kenaikan di tahun 2018 dibandingkan pada tahun 2017, sedangkan bulan Agustus sampai Desember 2018 rata-rata tingkat penghunian kamar mengalami penurunan.Hal ini menggambarkan bahwa adanya penurunan atau kejenuhan dalam industri pariwisata dan perhotelan.Walaupun tidak terjadi penurunan yang signifikan tetapi hal ini sangat perlu menjadi perhatian lebih oleh pemerintah dan stakeholder yang ada termasuk masyarakat secara luas.

Salah satu kemungkinan penyebab penurunan Tingkat Penghunian Kamar tersebut adalah dampak dari fenomena rangkaian gempa yang terjadi di Lombok Provinsi Nusa Tenggara Barat 29 Juli 2018 (M6,4), 05 Agustus 2018 (M7,0), 19 Agustus 2018 (M6,9). Seperti yang dikutip dalam berita online Antara Rabu, 5 September 2018 Slamet Fahrurrozi, Anggota Asosiasi Hotel Mataram (AHM), mengatakan gempa lombok berdampak dari sisi infrastruktur terkait kelaikan bangunan.Dampak bencana dirasakan cukup besar baik secara infrastruktur maupun beban pembiayaan serta operasional yang tidak sebanding dengan tingkat hunian hotel yang menurun tajam. Rata-rata hotel 
mengambil kebijakan untuk "mencutikan" karyawannya yang berstatus Daily Worker dan Outsourcing dengan tujuan mengurangi beban pembiayaan gaji karyawan. Hal ini dapat menyebabkan karyawan memiliki perasaan ketidakpastian dan kecemasan akan kesejahteraan mereka dan keberlangsungan pekerjaan mereka di hotel tersebut. Apalagi dengan status kekaryawanan mereka yang dari segi kesejahteraan akan berbeda dengan karyawan berstatus kontrak dan permanen.Pendapatan yang mereka dapatkan setiap bulannya dihitung berdasarkan hari masuk kerja. Sehingga ketika ada kebijakan hotel untuk mencutikan maka akan mempengaruhi pendapatan yang mereka terima.

Dalam penelitian (Chirumbolo \& Areni, 2005) mengatakan bahwa karena adanya tekanan kompetitif yang ekstrem, deregulasi dan kenaikan biaya, perusahaan terpaksa merestrukturisasi organisasi mereka, baik dalam hal bisnis, keuangan, proses dan struktur. Transformasi yang dilakukan ini telah mengubah sifat pekerjaan dan menyebabkan perasaan ketidakpastian, stres dan kecemasan bagi banyak pekerja tentang keberadaan dan fitur pekerjaan mereka. Dalam dua puluh tahun terakhir, penelitian telah menghasilkan bukti empiris yang luas tentang dampak negatif dari ketidakamanan pekerjaan pada sejumlah aspek yang terkait dengan kesejahteraan individu dan fungsi organisasi.

Menurut (de Cuyper, de Witte, Elst, \& Handaja, 2010)job insecurityatau rasa tidak aman dalam bekerja muncul karena banyaknya jenis pekerjaan yang sifatnya sesaat ataupekerjaan yang bersifat kontrak. Dalam penelitian ini lebih fokus pada karyawan dengan status Daily Worker dan Outsourcing.Semakin banyak jenis pekerjaan yang ada dengan waktu yang sementara menyebabkan semakin banyak karyawan mengalami job insecurity. Dalam (Liu, 2011) mengatakan bahwa karyawan yang menganggap organisasi tidak menyediakan pekerjaan yang aman, akan muncul rasa takut kehilangan pekerjaan dari karyawannya. Sehingga salah satu konsekuensi dari perasaan tidak aman karyawan tersebut adalah adanya niat untuk keluar dari organisasi/perusahaan tempat mereka bekerja atau turnover intentions.Turnover Intentions adalah kecenderungan atau niat karyawan untuk berhenti bekerja dari pekerjaannya secara sukarela menurut pilihannya sendiri(Morgan \& Zeffane, 2003).

Selain job insecurity, faktor lain yang mempengaruhi karyawan memiliki niat keluar dari perusahaannya adalah burnout. Burnout adalah sindrom psikologis yang berkepanjangan dan merupakan tanggapan atau respon terhadap stres dari interpersonal yang sudah kronis pada pekerjaan. Terdapat tiga dimensi kunci dari respon ini adalah kelelahan luar biasa, perasaan sinisme dan lepas dari pekerjaan, dan rasa ketidakefektifan dan kurangnya prestasi (Leiter \& Maslach, 2009).Hasil dari penelitian(Mansour \& Tremblay, 2018), pada situasi tertentu hasil dari burnout mengarahkan karyawan untuk meninggalkan pekerjaannya.Penelitian lain oleh (Babakus, Yavas, \& Ashill, 2011) menyatakan bahwa burnoutsering terjadi pada pekerja bagian pelayanan, dimana burnoutadalah bentuk ketegangan psikologis dan antara lain menyebabkan hasil yang tidak diinginkan seperti berkurangnya kinerja pekerjaan, ketidakpuasan kerja, berkurangnya kepuasan pelanggan, rendahnya tingkat komitmen organisasi, dan peningkatan absensi dan sebagai faktor utama dari adanya niat karyawan dalam meninggalkan pekerjaannya. 
Untuk itu dalam penelitian ini bertujuan untuk melihat pengaruh secara signifikanjob insecurity dan burnout terhadap turnover intentionsstudi pada karyawan dengan status Daily Worker dan Outsourcingpada hotel bintang 4 (empat) di Kota Mataram.

\section{Tinjauan Pustaka}

1) Landasan Teori

Turnover Intention adalah kecenderungan sikap atau tingkat di mana seorang karyawan memiliki kemungkinan untuk meninggalkan organisasi atau mengundurkan diridari pekerjaannya(Nissly, Mor Barak, \& Levin, 2005). Menurut Mobley dalam (Kuntary ibrahim, 2017), faktor-faktor yang mempengaruhi seseorang untuk pindah kerja (turnover intention) antara lain:

1) Karateristik Individu

Untuk mencapai tujuan organisasi, maka diperlukan adanya interaksi yang berkesinambungan dari unsur-unsur organisasi. Karakter individu yang mempengaruhi keinginan pindah kerja antara lain umur, pendidikan dan status perkawinan.

2) Lingkungan kerja

Lingkungan kerja dapat meliputi lingkungan fisik maupun sosial. Lingkungan fisik meliputi keadaan suhu, cuaca, kontruksi, bangunan, dan lokasi pekerjaan. Sedangkan lingkungan sosial meliputi sosial budaya di lingkungan kerjanya, besar atau kecilnya beban kerja, kompensasi yang diterima, hubungan kerjase-profesi, dan kualitas kehidupan kerjanya. Lingkungan kerja dapat mempengaruhi turnover intention pada karyawan. Hal ini dapat disebabkan apabila lingkungan kerja yang dirasakan oleh karyawan kurang nyaman sehingga menimbulkan niat untuk keluar dari perusahaan. Tetapi apabila lingkungan kerja yang dirasakan karyawan menyenangkan maka akan membawa dampak positif bagi karyawan, sehingga akan menimbulkan rasa betah bekerja pada perusahaan tersebut dan dapat menghilangkan keinginan pindah kerja (turnover intention).

Menurut (de Cuyper et al., 2010)job insecurityatau rasa tidak aman dalam bekerja muncul karena banyaknya jenis pekerjaan yang sifatnya sesaat ataupekerjaan yang bersifat kontrak. Dalam (Laine, van der Heijden, Wickstrom, Hasselhorn, \& Tackenberg, 2009)Ketidakamanan pekerjaan timbul dari ancaman kehilangan pekerjaan tertentu dan dapat menyebabkan hilangnya keamanan kerja jika pekerjaan berikutnya terbukti sulit untuk ditemukan oleh karyawan.Selanjutnya penelitian yang dilakukan oleh (Nugraha \& Garin, 2019) dan oleh (Academy, Academy, \& Trakt, 2013) juga menyatakan bahwa variabel job insecuritymemiliki pengaruh yang signifikan terhadapturnover intentions. Job Insecurityatau keresahan kerja diartikan sebagai pemicu stres psikososial yang berdampak pada kesehatan dan kesejahteraan, kepuasan kerja, komitmen organisasi, dan niat untuk meninggalkan pekerjaan dan / atau organisasi. Banyak peneliti dan akademika yang menjadikan niat turnover sebagai subjek penelitian dikarenakan banyak hasil negative yang ditimbulkan akibat dari karyawan yang melakukan turnover tersebut (Jehanzeb, Rasheed, \& Rasheed, 2013).

\section{H1 : Job Insecurity berpengaruh positif signifikan terhadap Turnover Intentions.}


Dalam (Mansour \& Tremblay, 2018) mengungkapkan bahwa pentingnya stress dalam hospitality industry tetapi itu menjadi pemicu timbulnya burnout sehingga berdampak pada karyawan memilih untuk meninggalkan pekerjaan mereka.Menurut(Rouleau, Fournier, Philibert, Mbengue, \& Dumont, 2012)burnout adalah istilah yang menggambarkan kondisi emosional seseorang yang merasa lelah dan jenuh secara mental, emosional dan fisik sebagai akibat tuntutan pekerjaan yang meningkat. Fenomena ini terjadi ketika seorang karyawan mengalami beban kerja yang berlebih, lingkungan kerja yang tidak memadai, dan kurangnya dukungan sosial dari keluarga, rekan sekerja, atasan, maupun organisasi. Terdapat penelitian yang dilakukan oleh (Zhang \& Feng, 2011) yang menyatakan bahwa terdapat pengaruh positif dan signifikan burnoutterhadap turnover intentions.

\section{H2 : Burnout berpengaruh positif signifikan terhadap Turnover Intentions.}

Berikut adalah Rerangka konseptual penelitian berdasarkan teori dan penelitian terdahulu :

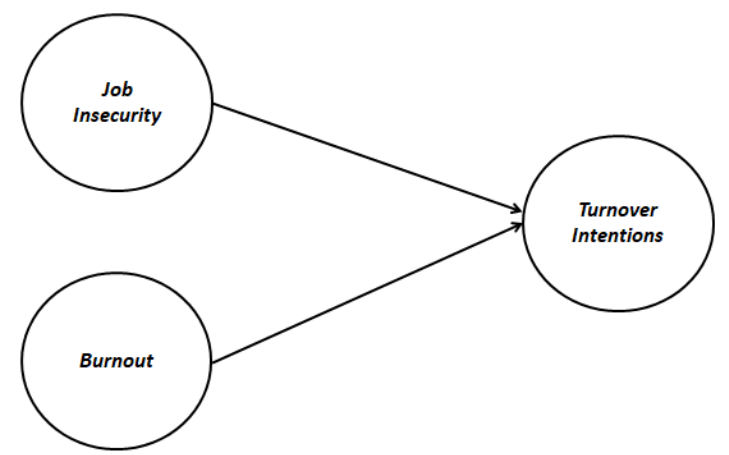

\section{Gambar 1. Rerangka Konseptual Penelitian}

\section{Metode Penelitian}

Penelitian ini adalah penelitian kausal dimana penelitian kausal merupakan penelitian yang bertujuan untuk mengetahui hubungan sebab akibat antara dua variabel atau lebih" (Silalahi, 2010:33).Dalam penelitian ini akan dapat menunjukkan "PengaruhJob Insecurity dan Burnout Terhadap Turnover IntentionsStudi Pada Karyawan Daily Worker dan OutsourcingHotel Bintang 4 (Empat) Di Kota Mataram".Adapun populasi dalam penelitian merupakan seluruh karyawan bagian operasional yang langsung berhadapan dengan tamu/guest contact. Karyawan tersebut adalah karyawan di 5 departemen yaitu Front Office, Food \& Beverage Service, Food \& Beverage Product, Housekeeping, dan Engineering dengan status Daily Worker danOutsourcing pada kelima departemen di atas di Lombok Raya Hotel berjumlah 35 orang dan jumlah karyawan pada Golden Palace Hotel Lombok sebanyak 51 orangdengan rincian status Daily Worker sejumlah 39 orang dan Outsourcing 12 orang. Metode penentuan sampel adalah sampel jenuh (sensus) dengan total jumlah karyawan yang menjadi sampel dalam penelitian ini sebesar 86 orang.

Jenis data dalam penelitian ini adalah data kualitatif yaitu data yang tidak berbentuk angka namun berupa uraian atau penjelasan yang berhubungan dengan penelitian sehingga dapat ditarik kesimpulan yang dirubah menjadi data kuantitatif yaitu data yang berbentuk angka-angka dan secara langsung dapat di diukur.Sumber data yang 
digunakan dalam penelitian ini terdiri dari 2 sumber yaitu sebagai berikutData Primer yaitu data yang diperoleh langsung dari responden yang menjadi subjek dalam penelitian. Data primer diperoleh dengan menyebarkan kuesioner kepada karyawan hotel bintang 4 (empat) di Kota Mataram dan Data Sekunder yaitu data pendukung yang diperoleh dari tempat penelitian, jurnal, buku-buku literature dan dokumen lainnya yang ada hubungannya dengan masalah penelitian. Teknik pengumpulan data menggunakan wawancara, teknik dokumentasi dan angket serta alat pengumpulan data dalam penelitian ini adalah Teknik wawancara membutuhkan alat rekam untuk membantu peneliti mengingat detail dari wawancara, Teknik dokumentasi membutuhkan alat tulis dan buku tulis untuk pencatatan hasil wawancara dan pencatatan atas dokumen yang dimiliki obyek penelitian, Teknik angket menggunakan kuesioner sebagai alat pengumpulan data yang akan diberikan kepada responden untuk melihat "PengaruhJob Insecurity Dan Burnout Terhadap Turnover IntentionsStudi Pada Karyawan Daily Worker Dan OutsourcingHotel Bintang 4 (Empat) Di Kota Mataram". Menurut Silalahi (2010:296), kuesioner merupakan satu set tulisan tentang pertanyaan yang diformulasikan supaya responden mencatat jawabannya, alternatif ditentukan secara terbuka dan pertanyaan tentang indikator konsep.

Dalam memberikan pembobotan pada masing-masing variabel digunakan skala lima tingkat yang terdiri dari sangat setuju, setuju, cukup, tidak setuju dan sangat tidak setuju. Hasil uji reliabilitas instrumen penelitian menunjukkan bahwa semua item pada variabel penelitian yang digunakan reliabel karena nilai Cronbach's Alphanya di atas 0,6, sedangkan hasil uji validitas instrumen penelitian dengan menggunakan teknik korelasi Product Moment Pearson menunjukkan bahwa semua item variabel penelitian yang digunakan valid, dengan nilai lebih besar dari 0,3, sehingga semua item variable dapat dilanjutkan untuk dianalisa. Analisis data dalam penelitian ini menggunakan Partial Least Square.

\section{Hasil Dan Pembahasan \\ Uji Asumsi Linearitas}

Uji asumsi linearitas digunakan untuk mengetahui apakah model diperoleh telah tepat dalam menggambarkan hubungan antar variabel sehingga dikategorikan keladam model yang baik atau fit. Dasar pengujian adalah dengan metode Curve Fit yang dihitung menggunakan software SPSS. Keputusan apakah hubungan antar variabel tersebut linear menggunakan $p=5 \%$. Hasil pengujian linearitas hubungan antar variabel laten disajikan pada tabel berikut :

\section{Tabel 2}

Hasil Pengujian Asumsi Linearitas

\begin{tabular}{|l|c|c|}
\hline \multicolumn{1}{|c|}{ Hubungan Antar Variabel } & Signifikansi & Keterangan \\
\hline Job Insecurity $\rightarrow$ Turnover Intentions & 0,002 & Linear \\
\hline Burnout $\rightarrow$ Turnover Intentions & 0,000 & Linear \\
\hline
\end{tabular}

Sumber : Data Primer diolah 
Jurnal Target, Vol. 1, No. 2, 2019

Tampak pada tabel bahwa semua bentuk hubungan antar variabel dalam model struktural adalah linear berdasarkan tingkat signifikansinya lebih kecil dari 5 persen $(\mathrm{p}<0,05)$. Dengan demikian asumsi linearitas pada model struktural terpenuhi.

\section{Evaluasi Measurement (Outer Model)}

\section{Uji Validitas Konvergen}

Berdasarkan hasil olah data menggunakan PLS, nilaiouter loadingsdapat dilihat dibawah ini :

Tabel 3

Nilai Outer Loading

\begin{tabular}{|l|l|l|l|}
\hline & Burnout & Job Insecurity & Turnover Intentions \\
\hline X1 01 & & 0.540712 & \\
\hline X1 02 & & 0.715436 & \\
\hline X1 03 & & 0.606986 & \\
\hline X1 04 & & 0.794214 & \\
\hline X1 05 & & 0.771557 & \\
\hline X2 01 & 0.417580 & & \\
\hline X2 02 & 0.793242 & & \\
\hline X2 03 & 0.810525 & & \\
\hline X2 04 & 0.553477 & & \\
\hline X2 05 & 0.555170 & & \\
\hline X2 06 & 0.745233 & & \\
\hline X2 07 & 0.771520 & & \\
\hline X2 08 & 0.661863 & & \\
\hline X2 09 & 0.793242 & & \\
\hline X2 10 & 0.810525 & & \\
\hline X2 11 & 0.759200 & & \\
\hline X2 12 & 0.798944 & & \\
\hline X2 13 & 0.785838 & & \\
\hline X2 14 & 0.731917 & & \\
\hline X2 15 & 0.798107 & & \\
\hline X2 16 & 0.363462 & & \\
\hline X2 17 & 0.596923 & & \\
\hline X2 18 & 0.743170 & & \\
\hline X2 19 & 0.785838 & & \\
\hline Y 01 & & & \\
\hline
\end{tabular}


Jurnal Target, Vol. 1, No. 2, 2019

\begin{tabular}{|c|l|l|l|}
\hline Y 02 & & & 0.786678 \\
\hline Y 03 & & & 0.795400 \\
\hline Y 04 & & & 0.561461 \\
\hline Y 05 & & & 0.607032 \\
\hline Y 06 & & & 0.739533 \\
\hline Y 07 & & & 0.730577 \\
\hline Y 08 & & & 0.623714 \\
\hline Y 09 & & & 0.729397 \\
\hline Y 10 & & & 0.547995 \\
\hline
\end{tabular}

Sumber : Data Primer diolah

Berdasarkan table di atas dapat dilihat bahwa semua indikator baik dari variabel $J o b$ Insecurity, Burnoutdan Turnover Intentions memiliki nilai outer loadings di atas 0,3 sehingga tidak ada indikator yang perlu didrop (dibuang) dan semua indikator diikutsertakan dalam pengolahan data selanjutnya.

\section{Uji Validitas Diskriminan}

Berdasarkan hasil olah data menggunakan PLS, nilaiAVE yang didapatkandapat dilihat dibawah ini :

\section{Tabel 4}

Uji Validitas Diskriminan

Tabel Nilai Square Root of Average Variance Extract (AVE) Variabel Laten

\begin{tabular}{|c|c|c|c|}
\hline Variabel & AVE & $\sqrt{\text { AVE }}$ & Keterangan \\
\hline Job Insecurity & 0,480 & 0,692 & Valid \\
\hline Burnout & 0,506 & 0,711 & Valid \\
\hline Turnover Intentions & 0,472 & 0,687 & Valid \\
\hline
\end{tabular}

Sumber : Data Primer diolah

Berdasarkan uji validitas diskriminan pada tabel diatas dapat diketahui bahwa akar AVE masing-masing lebih besar dari 0,5 sehingga dapat disimpulkan bahwa variabel yang digunakan pada penelitian adalah valid. Seluruh variabel yang dianalisis lebih besar dari nilai korelasi tertinggi antar masing-masing variabel independen dengan variabel lainnya.

\section{Reliabilitas Komposit}

Variabel dikatakan memiliki reliabilitas yang tinggi jika nilai composite reliability di atas 0,70 . Pada tabel akan disajikan nilai composite reliability:

Tabel 5

Nilai Composite Reliability

\begin{tabular}{|c|c|}
\hline Variabel & Composite Reliability \\
\hline Job Insecurity & 0,819 \\
\hline Burnout & 0,949 \\
\hline Turnover Intentions & 0,898 \\
\hline
\end{tabular}

Sumber : Data Primer diolah 
Nilai reliabilitas komposit yang ditunjukkan pada tabel di atas untuk setiap konstruk menunjukkan bahwa konstruk Job Insecurity, Burnout dan Turnover Intentions adalah reliabel.

Berdasarkan hasil evaluasi secara keseluruhan, baik convergent dan discriminant validity dan composite reliability yang telah dipaparkan di atas, maka dapat disimpulkan bahwa indikator-indikator sebagai pengukur variabel laten merupakan pengukur yang valid dan reliabel.

\section{Evaluasi Model Struktural (Inner Model)}

Penilaian terhadap model structural atau inner model dilakukan untuk melihat hubungan antar konstruk, nilai signifikansi dan R-Square model penelitian.

Tabel 6

Nilai R-Square konstruk dependen

Sumber: Data Primer Diolah

\begin{tabular}{|c|c|}
\hline Variabel & R-Square \\
\hline Turnover Intentions & 0,661 \\
\hline
\end{tabular}

Nilai Q-Square dapat diperoleh melalui rumus :

$\mathrm{Q}^{2}=1-\left(1-\mathrm{R}_{1}^{2}\right)\left(1-\mathrm{R}_{2}^{2}\right) \ldots . .\left(1-\mathrm{Rp}^{2}\right)$.

Berdasarkan rumus tersebut maka nilai Q-Square pada penelitian ini adalah $\mathrm{Q}^{2}=1-\left(1-0,661^{2}\right)=43,629 \%$.

Nilai Q-Square diketahui sebesar 0,436291 atau 43,6\% untuk Turnover Intentions sebagai variabel independen yang memberikan pengaruh terhadap Job Insecurity dan Burnout.Berdasarkan hasil perhitungan ini juga memberikan arti bahwa masih ada 29,2\% variabel lain yang dapat mempengaruhi turnover intentions karyawan pada hotel bintang 4 (empat) di Kota Mataram diluar model yang tidak diteliti. Misalnya kepemimpinan, kompensasi, dukungan sosial, kepuasan kerja dan komitmen organisasional.

\section{Pengujian Koefisien Jalur}

Hasil pengujian hubungan antar variabel penelitian dapat dilihat dari nilai koefisien jalur dan titik kritis (t-statistic) yang signifikan pada $\alpha=0,05$.

\section{Tabel 7}

Hubungan Antar Variabel

\begin{tabular}{|c|l|c|c|c|}
\hline No & \multicolumn{1}{|c|}{ Hubungan Antar Variabel } & $\begin{array}{c}\text { Koefisien } \\
\text { Jalur }\end{array}$ & $\begin{array}{c}\text { T- } \\
\text { statistik }\end{array}$ & Kesimpulan \\
\hline 1 & Job Insecurity $\rightarrow$ Turnover Intentions & 0,176 & 2,068 & Signifikan \\
\hline 2 & Burnout $\rightarrow$ Turnover Intentions & 0,723 & 9,512 & Signifikan \\
\hline
\end{tabular}

Sumber : Data Primer diolah

Tabel 7 di atas menunjukkan bahwa dari 2 hubungan antar variabel yang diajukan keduanya memiliki pengaruh yang signifikan. Adapun diagram jalur pada hubungan antar variabel tampak pada gambar berikut : 


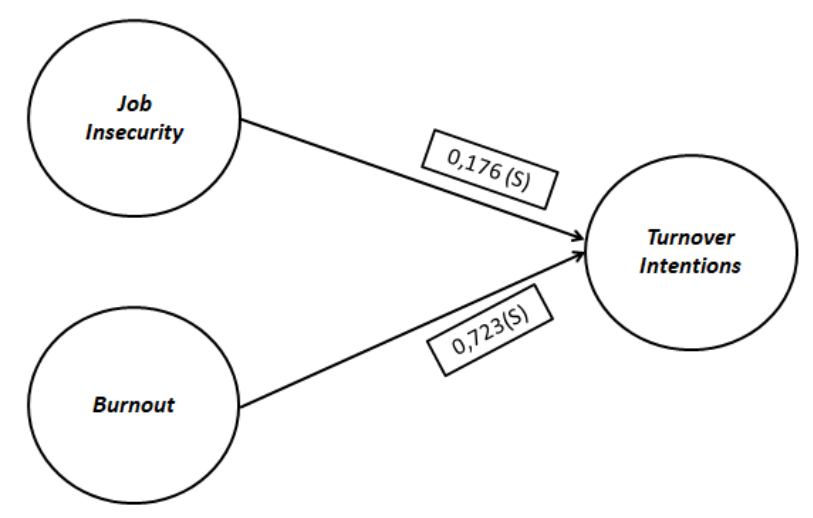

Sumber : Data Primer Diolah

Keterangan : $\mathrm{S}=$ Signifikan ;

\section{Gambar 2. Diagram Jalur Hasil Pengujian Hipotesis}

Dari tabel 8 dan gambar 1 di atas menunjukkan bahwa dari 2 hubungan antar variabel yang diajukan semuanya memiliki hubungan antar variabel yang signifikan. Penjelasannya sebagai berikut :

\section{a. Pengujian Hipotesis 1 : Pengaruh Job Insecurity terhadap Turnover Intentions}

Hipotesis 1 menyatakan bahwa Job Insecurity berpengaruh positif signifikan terhadap turnover intentions. Hasil uji terhadap koefisien parameterantara stres terhadap turnover intentions menunjukkan adanya pengaruh positif dengan nilai koefisien 0,176 dengan nilai t statistic sebesar 2,068 menunjukkan pengaruhnya signifikan. Nilai t statistic tersebut berada diatas nilai kritis 1,680, dengan demikian Ha diterima. Hal ini menunjukkan bahwajob insecurity berpengaruh positif dan signifikan terhadap turnover intentions.

Hasil analisis data menunjukkan bahwa job insecurityberpengaruh positif dan signifikan terhadap turnover intentions. Hal ini berarti jika job insecurityseorang karyawan pada hotel bintang 4 (empat) di Kota Mataram tinggi maka akan tinggi pula turnover intentions yang dirasakan oleh karyawan tersebut begitupun sebaliknya.Hal ini mengindikasikan tanggapan karyawan mengenai job insecurity yang dirasakannya rendah, karyawan merasa ada perkembangan karir di hotel tempat bekerjanya, karyawan tidak merasa ada ancaman di pekerjaannya yang membuat karyawan tersebut berniat meninggalkan pekerjaannya yang sekarang. Karyawan merasa memiliki kepentingankepentingan tertentu mengenai potensi dari setiap peristiwa yang terjadi di dalam perusahaan.

\section{b. Pengujian Hipotesis 2 : Pengaruh Burnout Terhadap Turnover Intentions}

Hipotesis 2 menyatakan bahwa burnout berpengaruh positif signifikan terhadap turnover intentions. Hasil uji terhadap koefisien parameterantara burnout terhadap turnover intentions menunjukkan adanya pengaruh positif dengan nilai koefisien 0,723 dan nilai $t$ statistic sebesar 9,512menunjukkan pengaruhnya signifikan. Nilai t statistic tersebut berada di atas nilai kritis 1,680, dengan demikian Ha diterima. Hal ini menunjukkan bahwa burnout berpengaruh positif dan signifikan terhadap turnover intentions. 
Hasil analisis data menunjukkan bahwa burnout berpengaruh positif dan signifikan terhadap turnover intentions. Hal ini berarti jika burnout seorang karyawan pada hotel bintang 4 (empat) di Kota Mataram tinggi maka akan tinggi pula turnover intentions yang dirasakan oleh karyawan tersebut begitupun sebaliknya.Hal ini mengindikasikan tanggapan karyawan mengenai burnout yang dirasakannya rendah, karyawan tidak memiliki perasaan emosi pada diri sendiri, mereka tidak merasa tak berdaya di akhir hari kerja bahkan mereka tidak merasa lelah ketika bangun di pagi hari, mereka tidak merasa frustasi atas pekerjaannya, mereka nyaman terhadap pekerjaanya, mereka menjadi lebih perasa dan sensitif terhadap orang lain yang berdampak mereka peka terhadap tamu dan mudah memahami apa yang diinginkan oleh tamu, mereka tidak merasa tegang bekerja dengan orang-orang sepanjang hari, mereka juga peduli terhadap pekerjaan orang lain, memperlakukan pelanggan secara dua arah, mereka merasa bekerja sesuai dengan beban kerja yang seharusnya diterima, mereka tetap memiliki perasaan untuk saling memahami masalah orang lain (rekan kerja), secara tenang dan efektif dapat menghadapi masalah yang terjadi, selalu bersemangat dalam bekerja, dan tidak merasa diujung tanduk karena dapat mengendalikan kelelahannya menjadi hal yang positif.

\section{Simpulan}

Hasil analisis dan pembahasan yang telah diuraikan sebelumnya maka dapat ditarik kesimpulan bahwa Job Insecurity berpengaruh positif dan signifikan terhadap turnover intentions dan Burnout berpengaruh positif dan signifikan terhadap turnover intentions.

\section{Implikasi}

Implikasi praktis Hasil penelitian ini memberi sumbangan untuk pengambilan keputusan terkait turnover intention. Hasil penelitian ini diharapkan bisa menjadi masukan bagi perusahaan untuk dapat mengontrol tingkat keamanan kerja dan kejenuhan karyawan agar mengurangi resiko turnover karyawan yang memiliki keahlian dan kompeten dalam bekerja.

\section{Keterbatasan Dan Saran}

Berdasarkan pembahasan dan kesimpulan yang telah dikemukakan sebelumnya, maka saran dari penelitian ini adalah untuk mengelola dan mempertahankan karyawan pihak manajemen hotel bintang 4 (empat) di Kota Mataram perlu menyediakan jenjang karir yang jelas untuk karyawan dan mengambil kebijakan terbaik untuk segala situasi yang terjadi di perusahaan dan tidak berdampak merugikan karyawan serta lebih memperhatikan karyawan dengan gejala burnoutakibat kejenuhan yang dirasakan akibat dari menurunnya tingkat hunian kamar. Karyawan akan merasakan berkurangnya prestasi diri dan tidak ada sarana untuk mengembangkan potensi yang ada. Peneliti selanjutnya dapat menambahkan variabel independen selain job insecurity atau menambah variabel mediasinya, perlu dilakukan penelitian terhadap seluruh karyawan pada seluruh hotel di Kota untuk gambaran hasil penelitian yang lebih luas. 
Jurnal Target, Vol. 1, No. 2, 2019

\section{Daftar Pustaka}

Babakus, E., Yavas, U., \& Ashill, N. J. (2011). Service worker burnout and turnover intentions: Roles of person-job fit, servant leadership, and customer orientation. Services Marketing Quarterly, 32(1), 1731. https://doi.org/10.1080/15332969.2011.533091

Chirumbolo, A., \& Areni, A. (2005). The influence of job insecurity on job performance and absenteeism: The moderating effect of work attitudes. SA Journal of Industrial Psychology, 31(4), 65-71. https://doi.org/10.4102/sajip.v31i4.213

de Cuyper, N., de Witte, H., Elst, T. Vander, \& Handaja, Y. (2010). Objective threat of unemployment and situational uncertainty during a restructuring: Associations with perceived job insecurity and strain. Journal of Business and Psychology, 25(1), 75-85. https://doi.org/10.1007/s10869-009-9128-y

Hendrayani, D. (2013). Pengaruh Komitmen dan Job Insecurity Terhadap Intensi Turnover Pada Operator Garuda Call Center. X(1), 1-21.

Jehanzeb, K., Rasheed, A., \& Rasheed, M. F. (2013). Organizational Commitment and Turnover Intentions: Impact of Employee's Training in Private Sector of Saudi Arabia. International Journal of Business and Management, 8(8). https://doi.org/10.5539/ijbm.v8n8p79

Kuntary ibrahim, I. D. (2017). Pengaruh Stres Kerja Terhadap Turnover Intentions Yang Dimediasi Oleh Burnout" (Studi Pada Karyawan Hotel Bintang 4 (Empat) Di Kota Mataram). Jmm Unram - Master of Management Journal, 6(2), 1-16. https://doi.org/10.29303/jmm.v6i2.103

Laine, M., van der Heijden, B. I. J. M., Wickstrom, G., Hasselhorn, H. M., \& Tackenberg, P. (2009). Job insecurity and intent to leave the nursing profession in Europe. International Journal of Human Resource Management, 20(2), 420-438. https://doi.org/10.1080/09585190802673486

Leiter, M. P., \& Maslach, C. (2009). Nurse turnover: The mediating role of burnout. Journal of Nursing Management, 17(3), 331-339. https://doi.org/10.1111/j.1365-2834.2009.01004.x

Liu, R. (2011). The mid-high-end talent's job embeddedness, turnover intention, and Cooperative Behavior: Job insecurity as a moderator. International Conference on Management and Service Science, MASS 2011. https://doi.org/10.1109/ICMSS.2011.5998071

Mansour, S., \& Tremblay, D. G. (2018). Work-family conflict/family-work conflict, job stress, burnout and intention to leave in the hotel industry in Quebec (Canada): moderating role of need for family friendly practices as "resource passageways." International Journal of Human Resource Management, 29(16), 2399-2430. https://doi.org/10.1080/09585192.2016.1239216

Morgan, D. E., \& Zeffane, R. (2003). Employee involvement, organizational change and trust in management. International Journal of Human Resource Management, 14(1), 55-75. https://doi.org/10.1080/09585190210158510

Nissly, J. A., Mor Barak, M. E., \& Levin, A. (2005). Stress, social support, and workers' intentions to leave their jobs in public child welfare. Administration in Social Work, 29(1), 79-100. https://doi.org/10.1300/J147v29n01_06

Nugraha, E., \& Garin, H. M. (2019). the Influence of Career Growth and Job Insecurity on Turnover Intention of Outsourcing Workers in Port Services Field Companies. Russian Journal of Agricultural and SocioEconomic Sciences, 90(6), 270-275. https://doi.org/10.18551/rjoas.2019-06.33

Rouleau, D., Fournier, P., Philibert, A., Mbengue, B., \& Dumont, A. (2012). The effects of midwives' job satisfaction on burnout, intention to quit and turnover: a longitudinal study in Senegal. Human Resources for Health, 10, 1-14. https://doi.org/10.1186/1478-4491-10-9

Zhang, Y., \& Feng, X. (2011). The relationship between job satisfaction, burnout, and turnover intention among physicians from urban state-owned medical institutions in Hubei, China: A cross-sectional study. BMC Health Services Research, 11, 1-13. https://doi.org/10.1186/1472-6963-11-235 